\title{
Outcomes of Feeding Training to Mothers Having Child with Cerebral Palsy Admitted at A Tertiary Level Hospital in Bangladesh
}

\author{
Dhananjoy Das ${ }^{1 *}$ \\ Tanzida Zaman ${ }^{1}$ \\ Mohammad Shameem Hasan ${ }^{2}$ \\ Tanuka Barua ${ }^{3}$ \\ Mahmood A Chowdhury ${ }^{3}$ \\ Autism \& Child Development Center \\ Chattagram Maa-Shishu-O-General Hospital \\ Chittagong, Bangladesh. \\ ${ }^{2}$ Department of Pediatrics \\ Chittagong Medical College \\ Chittagong, Bangladesh. \\ ${ }^{3}$ Department of Pediatrics \\ Chattagram Maa Shishu-O-General Hospital \\ Chittagong, Bangladesh.
}

\section{*Correspondence to:}

\section{Dr. Dhananioy Das}

Registrar

Autism \& Child Development Center and

Child Neurology Unit

Chattagram Maa Shishu-O-General Hospital

Chittagong. Bangladesh.

Mobile : +8801819859016

E-mail:dhananjoy_das@y-mail.com

www.banglajol.info/index.php/CMOSHMC

\begin{abstract}
Background: The majority of children with Cerebral Palsy have feeding difficulties. It has a great impact on growth and development in children with cerebral palsy. Feeding difficulties may leads to chronic respiratory disease, malnutrition and reduce quality of life of both children and caregiver. Feeding difficulties cause stressful meal time for caregivers and fear of food for children. In well resource country many hi-tech equipments for the management of feeding difficulties are available but which is not available in low resource country like Bangladesh. Though some of low tech approaches have started a little but the effectiveness or outcomes of these technologies are not evaluated. This study is aimed to evaluate the effect of feeding training on feeding difficulties in children with cerebral palsy. Methods: This is a quasi experimental study. Twenty children with cerebral palsy aged $2-9$ years having feeding difficulties enrolled as study subjects. Initially degree of feeding difficulties were assessed by evaluating body posture and frequency of aspiration during feeding which is scored according to the response of the child. After giving feeding training to the mother feeding difficulties were reevaluated. Mean score of feeding difficulties before and after intervention were compared by paired ' $t$ ' test. Results were analyzed by SPSS. Results: Among the study subject $14(70 \%)$ were male and $6(30 \%)$ were female. Most of them were found to have hemiplegic CP $7(35 \%)$. The mean score in terms of positioning and frequency of aspiration were significantly changed after intervention (14.15 vs. $15.85 \mathrm{p}=<0.0005),(11.6$ vs 15.5 $\mathrm{p}=<0.0005)$. Conclusion: Low-tech strategies and therapies are helpful for the management of feeding difficulties in children with cerebral palsy. Foods and drinks modifications should need to get extra attention for the nutritional improvements of those children. Government and international and national health NGOs should studied more about these low tech strategies to improve the condition of the children with cerebral palsy and to reduce the stress and sufferings of the parents.
\end{abstract}

Key words: Feeding difficulties; Feeding training; Low tech strategies.

\section{INTRODUCTION}

Cerebral Palsy (CP) can be defined as a group of disorders of movement of limbs and muscle, hearing and vision and posture. It's because of damage to the developing brain. This may happen before or during birth or within the first few days after birth ${ }^{1}$. In Bangladesh a population based study has been conducted and showed that, children aged 2-9 years expected the prevalence of severe disability to be 22 in every 1000 children ${ }^{2}$. The total number of children with cerebral palsy in Bangladesh is about 2.8 million among 144,109,214 populations ${ }^{3}$. Among them maximum children have feeding difficulties. As feeding is a fundamental right to every human and its importance for survival is beyond an explanation, so incase of 
children with disability or cerebral palsy should get extra attention in feeding. Per day a child with cerebral palsy can take three and half hours to feed ${ }^{4}$. Mothers have not enough time to feed their child and as result child with cerebral palsy get's a poor health condition. In developing countries like Bangladesh, the child with $\mathrm{CP}$ is treated like burden of care falls almost entirely on the family. $90 \%$ of these children are reported that having feeding difficulties ${ }^{5}$. This feeding difficulty is leading to moderate to severe malnutrition and limited fluid intake. This problem leads to decrease in functioning, health \& well-being ${ }^{6,7}$. To decrease the malnutrition and mortality rate of children with CP, Child Development Center (CDC) Chattagram Maa Shishu-O-General Hospital, Bangladesh took some innovative steps as their clinical activities and serve successfully. There are already a feeding training is running at CDC, Chattagram Maa Shishu-O-General Hospital The main aim of the training is to educate and train about special feeding techniques and nutrition to manage the feeding difficulties children with CP. In this study we tried to find out the exact outcome of the training. As there is already a feeding training is running at $\mathrm{CDC}$, we tried to find out the exact outcome or the efficacy of the feeding training.

\section{MATERIALS AND METHODS}

This is a quasi experimental study carried out in the Child Development Center, Chattagram Maa-O-Shishu Hospital during the time period of December 2015. Twenty patient with different types of cerebral palsy with feeding difficulties aged 2-9 years attended in the child neurology OPD enrolled as study subject. The child who were diagnosed as progressive or metabolic disorder or chronically sick or having any congenital syndrome were excluded from the study. Presence of feeding difficulties was assessed by a checklist which was developed by Adams $\mathrm{M}$ et $\mathrm{al}^{8}$. The checklist involved some questionnaires. For example does the child have any problems with eating and drinking or not, if the child eats the same food as other children with the same age or not, if the child coughs or chokes while eating or drinking or not, if the child is not growing or putting on weight like other children or not, if the child dribbles or drools or not. Degree of feeding difficulties was measured by position of head and body and signs symptoms of aspiration during meal time. However to identify the degree of feeding difficulties position of body and head of the child were assessed in accordance with some questionnaires. For body if it is lying down or not, breast feeding position or not, sitting slouched or well supported, using special chair for feeding or not. For the head position if the head is very extended or slightly extended, if the head is neither extended nor flexed or slightly flexed etc. Similarly to measure the degree of sign symptom of aspiration mothers were asked some questionnaires like if the child coughed or had watery eyes, or is there any burping or fatigue or vomiting during meal time or not. If the response of the mother is "yes" then it was scored as 1 and if the response of the mother is "no" then it was scored as 2 . Initially score of feeding difficulties along with socio demographic data were recorded in the data collection form. After giving feeding training which involved some educational and practical session including how to provide lip / jaw support, how to modify suitable utensil, how to give low pelvic support and padded neck support etc and supervision of the feeding, one week apart feeding scores of feeding difficulties were measured again. After wards mean score of feeding difficulties were compared by paired ' $t$ ' test. Data analysis was done by Statistical Package for Social Sciences (SPSS) 17 version.

\section{RESULTS}

In this current study $14(70 \%)$ were male and 6(30\%) were female. Among all the participants 5(25\%) were diagnosed as Diplegic CP, 4 (20\%) were Quadriplegic CP, 7 (35\%) participants were diagnosed as Hemiplegic CP, Topographical category of $\mathrm{CP}$ could not be identified in $4(20 \%)$ participants.

The mean score of feeding difficulties in terms of positioning before implementation of feeding training was 14.15 and after applying the feeding training it was found 15.85. This difference is found to be statistically significant ( $p=<0.0005)$. There was significant increment of the scoring in the area of frequency of aspiration. The mean score before providing feeding training was 11.6 and after providing feeding training was $15.5 \mathrm{p}=<.0005$.

Table 1: Gender distribution of the study subject.

\begin{tabular}{lrr} 
Gender & Number & $\begin{array}{r}\text { Total } \\
\mathrm{n}=20\end{array}$ \\
Male & $\begin{array}{r}14 \\
(70 \%)\end{array}$ & $100 \%$ \\
Female & 06 & \\
& $(30 \%)$ & \\
\hline
\end{tabular}

Table 2 : Type of CP of the study subject.

\begin{tabular}{lccc} 
Type of CP & Number & $\begin{array}{c}\text { Total } \\
\text { percentage }\end{array}$ & $\begin{array}{c}\text { Total number of } \\
\text { study subject } \\
\text { n= 20 }\end{array}$ \\
\hline Hemiplegic CP & 7 & $35 \%$ & \\
Quadriplegic CP & 4 & $20 \%$ & \\
Diplegic CP & 5 & $25 \%$ & $100 \%$ \\
Un categorized & 4 & $20 \%$ & \\
\hline
\end{tabular}

Table 3 : Comparison of mean score in different areas of feeding difficulties after feeding training.

\begin{tabular}{lcccc}
$\begin{array}{l}\text { Areas of Feeding } \\
\text { Practices }\end{array}$ & \multicolumn{2}{c}{$\begin{array}{c}\text { Mean } \\
\text { Score }\end{array}$} & 't' value & ' $\mathbf{p}$ ' value \\
& Before & After & & \\
& $\begin{array}{l}\text { Feeding } \\
\text { Training }\end{array}$ & $\begin{array}{c}\text { Feeding } \\
\text { Training }\end{array}$ & & \\
& 14.15 & 15.85 & 4.99 & $<.0005$ \\
Positioning & 11.6 & 15.5 & 9.67 & $<.0005$
\end{tabular}


Figure 1: Comparison in scores in terms of position before and after feeding training of participants.

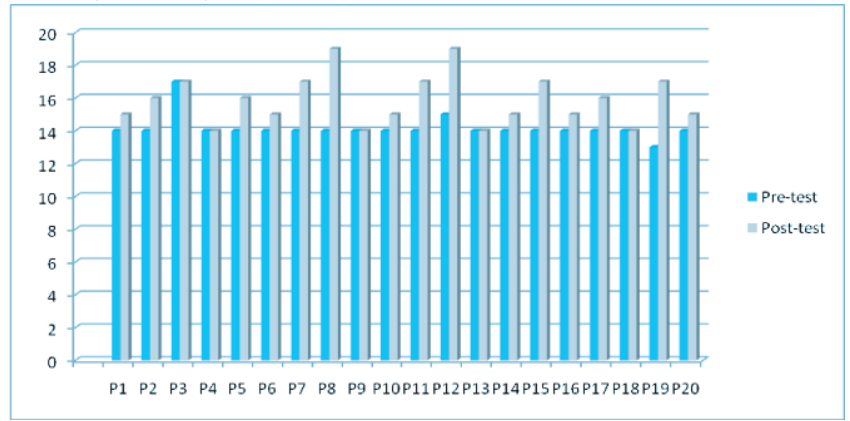

Figure 2: Comparison in scores in terms of aspiration before and after feeding training of participants.

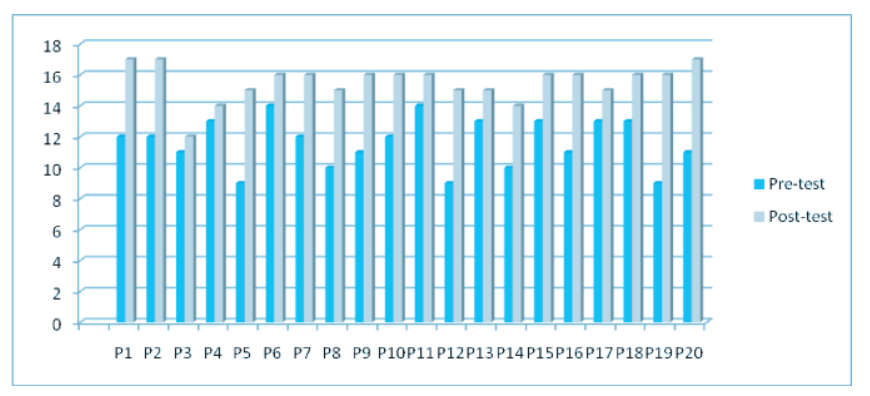

\section{DISCUSSION}

The aim of the study was to find out the outcomes of feeding training program for children with cerebral palsy who have feeding difficulties.

In this study among all the participants, 6 participants (30\%) were male and $14(70 \%)$ participants were female. The tendency to have cerebral palsy is with boys than from girls. This finding consistent with Centre of Rehabilitation for Paralysis (CRP) annual report ${ }^{9}$. Which revealed the total number of children with cerebral palsy in Bangladesh is about 2.8 million and the male female ratio is $3: 1$. So, the boys have more feeding difficulties than girls.

Among all the participants $85 \%$ children's age was between $1 \mathrm{yr}$ to $5 \mathrm{yr}$ and $15 \%$ children's age was $5 \mathrm{yr}$ to $9 \mathrm{yr}$. From the demographic information of the participants there is actually not any significant variation on severity of the feeding difficulties in case of variations of ages. In a population based study children aged 2-9 years in Bangladesh by Mobarak R et al. estimated the prevalence of moderate to severe disability with specially feeding problem due to cerebral palsy ${ }^{10}$. In a population based study by Adams MS et al. found that 28 children among 37 has been significantly improved after feeding training who have had moderate to severe CP and the investigator did not found any correlation between ages and feeding difficulties ${ }^{8}$. From this current study it has been found that, feeding difficulties does not depend on ages, because there was 20 children came up for feeding training and none of them have same age but some of them have the same frequency or level (Mild, moderate, severe) of feeding difficulties.
In terms of type of CP, 5 (25\%) participants were diagnosed as hemiplegic CP, 7 (35\%) were diagnosed with diplegic CP, 4 (20\%) participants were diagnosed with quadriplegic $\mathrm{CP}$, in 4 (20\%) participants type of CP could not be categorized ${ }^{11}$. There is no relationship between improvement and the types of $\mathrm{CP}$ as all children with different types of $\mathrm{CP}$ improve in different way. In different studies it was found that there is no relation between feeding difficulties and types of $\mathrm{CP}^{12,13}$. Physicians determine the types of $\mathrm{CP}$ depending upon the motor involvement, the feeding difficulties is depends upon mainly on structural differences and not determine by the types of $\mathrm{CP}^{14}$.

At the time of feeding before the feeding training, it has been found that the caregiver intended to feed their child in a wrong posture and incorrect trunk position and got a low score in both areas $^{15}$. In this study sample was provided low tech approaches (Detail in the methodology) through the feeding training. Sometimes a simple posture or use of special adaptive simple feeding equipment may dramatically improve the child's intake $^{16}$. However, after the feeding training, it has been found that the most of the participants score increased therefore the aimed areas for the study (Position and frequency of aspiration) improved. On the other hand before the feeding training it has been found a low score on aspiration that creates risk of aspiration pneumonia and chest infection also so many respiratory diseases ${ }^{17,18}$. After implementation of the intervention the score of reducing aspiration was increased.

In fact the importance of achieving appropriate positioning (Especially head positioning and posture) and as well as achieving an appropriate food modification that may take a perfect consistency for particular child for reducing risk of aspiration that caused feeding difficulties of children with $\mathrm{CP}$ are widely recognized ${ }^{19,20}$

It has been found that there is actually no strong connection between educational background and the feeding training that provided ${ }^{21}$. Each and all mothers have minimum knowledge to understand Bengali language so that directions which are given can be followed correctly. According to McConachie $\mathrm{H}$ et $\mathrm{al}^{22,23}$. Feeding training program can increase maternal knowledge and skills in handling their children with cerebral palsy and also improved the skills of feeding of the children with cerebral palsy.

After feeding training scores of feeding difficulties increased in 15 children. Among them seven patients with CP improved their position significantly. Sometimes a simple posture or use of special adaptive simple feeding equipment may dramatically improve the child's intake ${ }^{24,25}$. Through the training the children gained a set of new skills of positioning during feeding that improved feeding of the children with CP. Again before and after feeding training, score of frequency of aspiration has been improved too. Besides the increasing score after training mothers also reported that their children choke and cough much less than previous. That improvement made a 
relief of tension during feeding time. Mothers became less stress than before the training. Mothers also reported that their children cried a little during feeding time after the feeding. It has also observed that children with moderate to severe feeding difficulties who have severe choking and aspiration while they fed, made a great score that's showed a indicator of improvement. So that it can be concluded that significant improvements can be achieved in terms of feeding difficulties in a patients with $\mathrm{CP}$ after a minimum low cost training ${ }^{26}$.

\section{LIMITATION}

This study has some limitations, sample size is small and this study was conducted only in CDC, Chattagram Maa Shishu-OGeneral Hospital. Besides this study does not represent the mother's perception about the feeding training. After training program nutritional status could not be evaluated as it requires follow up.

\section{RECOMMENDATION}

There are millions number of children are suffering from cerebral palsy. Majority of them have feeding difficulties which led them to severe malnutrition. In this study it has been proved that feeding training can bring a significant improvement in feeding practices of those children who have feeding difficulties. And with the help of feeding training our one of the major issue 'malnutrition' for the children with cerebral palsy can be prevent.

\section{CONCLUSION}

In this study it has been showed that significant improvements in feeding difficulties can be achieved after a minimum of two low technology feeding training sessions. In this study only the two areas of feeding difficulties were focused specially for the improvement of feeding techniques but there are also many areas are present which needs advocacy. Advocacy is urgently required to increase awareness and support among our governments, health service commissioners and health providers at all levels, regarding the needs of children with disabilities and feeding difficulties and their caregivers, in order for services to be made available.

\section{DISCLOSURE}

All the authors declared no competing interest. 


\section{REFERENCES}

1. Workinger MS. Cerebral Palsy Resource Guide. New York: University of NY. 2005; 33-39.

2. Thomas GA, Trier E. Feeding your children with Cerebral Palsy in an appropriate manner. American Journal of Occupational Therapy.1998;2: 578.

3. Bailey MD. Research for the Health Professional. Philadelphia: Davis Company. 1997; 26-28.

4. Sullivan PB, Rosenbloom, L. Feeding the Disabled Child. UK: Mac Keith Press. 2006; 47-56.

5. Srivastava N, Sandhu A. Infant and Child Feeding Index. Indian Journal of pediatrics. 2006;73: 767-770.

6. Gisel EG, Tessier M J, Lapierre G, Seidman E, Drouin, E, Filion, G. Physical Occupational Therapy in Pediatrics: Feeding management of children with severe cerebral palsy and eating impairment: An exploratory study. Journal of pediatric Psychology. 1994;23: 19-21.

7. Johnson CB, Deitz, JC. Time use of mothers with preschool children. The American Journal of Occupational Therapy. 1985; $39: 578-583$.

8. Adams MS. Feeding difficulties in children with cerebral palsy: Low-cost caregiver training Dhaka, Bangladesh. City University London. 2011; 64-78.

9. $\quad$ CRP. Annual Report. Dhaka:CRP. 2007.

10. Mobarak R., Khan NZ, Munir S, Zaman SS, Mcconachie H. Predictors of stress in mothers of children with cerebral palsy in Bangladesh. Journal of Pediatric Psychology. 2000; 25: 427-433.

11. Black MM. Feeding problems: An ecological perspective. Journal of pediatric Psychology. 1994;24: 217-219.

12. Selley WG, Parrot LC, Lethbridge PC, Flack FC, Ellis RE, Johnson KJ et al. Dysphagia: Objective measures of dysphagia complexity in children related to suckle feeding histories gestational ages and classification of their cerebral palsy. Indian Journal of pediatrics. 2010; 16: 200-207.

13. Hurley KM, Black MM, Papas MA, Caulfield LE. Maternal symptoms of stress anxiety and depression are related to non-responsive feeding styles in a statewide. Sample of WIC participants. The journal of Nutrition. 2008; 138: 799-805.

14. Larnert G, Ekberg O. Positioning improves the oral and pharyngeal swallowing function in children with cerebral palsy. Acta Paediatrica. 1999;84: 689-692.

15. Akkok F. An overview of parent training and counseling with the parents of children. International Journal for the Advancement of Counseling. 1994;17: 129-138.

16. Khan NZ, Ferdous S, Munir S, Huq S, McConachie H. Mortality of urban and rural young children with cerebral palsy in Bangladesh. Developmental Medicine and Child Neurology. 1998; 40: 749-753.

17. Hicks MC. Research Methods for Clinical Therapists. London: Churchill Livingstone. 1999;3:84-86.

18. Levitt S. Treatment of Cerebral Palsy and motor delay. Germany: Berlin press. 28-32.

19. Neyerlin- Beale J, Sandra S. The impact of Community Occupational Therapy on Children with Disabilities and their carers. British Journal of Occupational Therapy. 2000;63: 373-379.

20. McConachie H, Huq S, Ferdous S, Zaman S, Khan NZ. A randomized controlled train of alternative modes of service propism to young children with cerebral palsy in Bangladesh. Journal of Pediatrics. 2000; 6: 769-776.

21. Reilly S, Skuse, D, Poblete X. Prevalence of feeding problems and oral motordysfunction in children with cerebral palsy: A community survey. Journal of Pediatrics. 1996;129: 877-882.

22. Reilly S, Skuse D. Characteristics and management of feeding problems of young children with cerebral palsy. Journal of Pediatrics. 1992; 34: 379-388.

23. Stanley FJ, Blair E, Alberman E. Cerebral Palsies: Epidemiology and Casual Pathways. London: Mac Keith Press. 2006;113 -117.

24. Stoner J, Baily R, Angell M, Robbins J, Polewski K. Perspective of Parents/Guardians of children with feeding/ swallowing problem, Journal of Physical and Development Disability. 2006; 18: 333.

25. Sullivan PB, Juszczak E, Bachlet AM, Thomas AG, Lambert B, Vernon-Roberts A et al. Developmental Medicine and Child Neurology: Impact of gastrostomy tube feeding on the quality of life of carers of children with cerebral palsy. UK: Mac Keith Press. 2008; 77-85.

26. Sullivan PB, Juszczak E, Bachlet A M, Lambert B, Vernon-Roberts A, Grant HW et al. Gastrostomy tube feeding in children with cerebral palsy: A prospective longitudinal study. Developmental Medicine and Child Neurology. 2005;47: 77-85. 